\title{
Abnormal Regulation of Extracellular Matrix and Adhesion Molecules in Corneas of Patients with Keratoconus
}

\author{
${ }^{1}$ Yelena Bykhovskaya, ${ }^{2}$ Anastasia Gromova, ${ }^{3}$ Helen P Makarenkova, ${ }^{4}$ Yaron S Rabinowitz
}

\section{ABSTRACT}

Aim: To identify changes in the expression of genes coding for extracellular matrix (ECM) proteins in patients with noninflammatory corneal disorder keratoconus (KC), patients with corneal scarring, and normal controls.

Materials and methods: Total ribonucleic acid extracted from corneal tissue of $13 \mathrm{KC}$ patients, 2 patients with corneal scaring, and 4 normal controls was analyzed using Human Extracellular Matrix \& Adhesion Molecules Profiler Polymerase Chain Reaction Array. Statistically significant changes in gene expression were identified using the Data Analysis software.

Results: Comparison of $\mathrm{KC}$ and control corneas with thresholds of 1.5 or greater fold change and a p-value of 0.05 or lower revealed 21 differentially expressed genes: 16 genes were downregulated and 5 were upregulated. Among transcripts downregulated in KC patients, we identified thrombospondin 1, disintegrin and metalloproteinase with thrombospondin motif 1 , secreted phosphoprotein 1, several collagens, and integrins. We found transforming growth factor beta-induced (TGFBI or $\mathrm{BIGH} 3$ ) gene was the most significantly upregulated transcript.

Conclusion: The development of $\mathrm{KC}$ results in deregulation of gene expression of ECM and adhesion molecules.

Clinical significance: Downregulation of collagens and upregulation of TGFBI repeatedly identified in KC patients may be used as clinical markers of the disease.

Keywords: Adhesion, Collagens, Extracellular matrix, Expression, Keratoconus, Laboratory research.

How to cite this article: Bykhovskaya $Y$, Gromova A, Makarenkova HP, Rabinowitz YS. Abnormal Regulation of Extracellular Matrix and Adhesion Molecules in Corneas of Patients with Keratoconus. Int J Kerat Ect Cor Dis 2016;5(2): 63-70.

Source of support: This study was supported by The Eye Defects Research Foundation Inc., the Skirball Fund for Molecular Ophthalmology, and the National Eye Institute grant R01-09052 (Y.S.R) and NEI 2R01-EY012383-11A1 (H.P.M.).

Conflict of interest: None

\footnotetext{
${ }^{1}$ Research Scientist, ${ }^{2}$ Graduate Student, ${ }^{3,4}$ Professor

${ }^{1,4}$ Department of Surgery and Board of Governors Regenerative Medicine Institute, Cedars-Sinai Medical Center, Los Angeles California, USA

${ }^{2,3}$ Department of Cell and Molecular Biology, The Scripps Research Institute, La Jolla, California, USA
}

Corresponding Author: Yelena Bykhovskaya, Research Scientist, Department of Regenerative Medicine, CedarsSinai Medical Center, Los Angeles, California, USA, Phone: +3102488566, e-mail: yelena.bykhovskaya@cshs.org

\section{INTRODUCTION}

Cornea is a highly differentiated tissue, rich in extracellular matrix (ECM) synthesized by its cell constituents: Epithelial cells, stromal keratocytes, and endothelial cells. The corneal multilayered epithelium plays a protective role; highly organized collagen fibrils of a stroma ensure a transparency, and a single layer of endothelium regulates water transport and corneal homeostasis. The corneal matrix constitutes a major part of corneal stroma and is characterized by a well-defined supramolecular structure that ensures both corneal transparency and its protective role.

Keratoconus (KC) is a complex genetic noninflammatory corneal dystrophy characterized by progressive corneal thinning, resulting in moderate to marked visual impairment. ${ }^{1}$ Recent genetic studies brought new insights into KC susceptibility genes, including identification of genes underlying both population variation in the central corneal thickness (CCT) and KC. ${ }^{2}$ Several KC genes identified to date include genes coding for ECM components and regulators, such as gene coding for type $\mathrm{V}$ collagen subunit 1 (COL5A1) ${ }^{3}$ collagen cross-linking enzyme lysyl oxidase, ${ }^{4,5} \mathrm{ZNF} 469{ }^{6,7}$ and potentially other collagens. ${ }^{8,9}$ Varying abnormalities in the expression of different ECM components were identified in corneas of patients with KC by immunostaining, ${ }^{10,11}$ proteome profiling, ${ }^{12,13}$ comparative transcriptome profiling, ${ }^{14,15}$ analysis of expression levels of individual genes, ${ }^{16}$ as well as in vitro studies of corneal stromal fibroblasts. ${ }^{17}$ In this study, we analyzed the expression of genes for cell-cell and cell-matrix interactions in corneal tissue from KC patients, small group of patients with corneal scarring secondary to radial keratotomy surgery, and healthy controls. We employed the Human Extracellular Matrix \& Adhesion Molecules RT2 Profiler PCR Array (Qiagen, Valencia, CA) based on the real-time quantitative polymerase chain reaction (qPCR) method and optimized to target the most relevant genes.

\section{MATERIALS AND METHODS}

\section{Subjects}

Clinically affected KC patients were recruited from the Cornea Genetic Eye Institute. Institutional Review Board approval and written informed consent were obtained 
from all subjects. The study was conducted in accordance with the provisions of the Declaration of Helsinki.

\section{Diagnosis}

The diagnosis of KC was based on the clinical examination that included slit-lamp biomicroscopy, cycloplegic retinoscopy, and fundus evaluations, and confirmed with videokeratography. The slit lamp biomicroscope was used to identify stromal thinning, Vogts' striae, and/a Fleischer ring. The retinoscopy examination was performed with a fully dilated pupil (20 minutes after phenylephrine $2.5 \%$ and cyclopentolate $1 \%$ drops had been instilled in the eye) to determine the presence or absence of retroillumination signs of $\mathrm{KC}$, such as the oil droplet sign and scissoring of the red reflex. Videokeratography evaluation was performed using the Topographic Modeling System (TOMEY, Nagoya, Japan). Subjects were assigned as having $\mathrm{KC}$ if they had at least one clinical sign and a confirmatory videokeratography map with an asymmetric bow-tie with skewed radial axis above and below the horizontal meridian pattern. ${ }^{1}$ Keratoconus grade was assigned based on the average central keratometry readings as follows: Mild: K1 <50D; moderate: K1 > 50D but <55D; moderate-severe: K1 55-60D; severe: $>60 \mathrm{D}$. Corneal scarring secondary to radial keratotomy surgery was diagnosed based on the slit lamp evaluation by the corneal clinician.

\section{Tissue Collection and Processing}

Corneal buttons from patients with $\mathrm{KC}$ and corneal scarring were obtained during penetrating keratoplasty. Tissue was kept on ice and was generally processed within 3 hours of surgical removal, but no later than within 24 hours. Corneal buttons were stored at $-80^{\circ} \mathrm{C}$ in a freezer or in ribonucleic acid (RNA)-later reagent at $-20^{\circ} \mathrm{C}$ in a freezer.

Corneal buttons of normal controls were purchased from Minnesota Lions Eye Bank (St. Paul, MN, USA). They were shipped on ice and received within 24 hours of removal.

\section{Ribonucleic Acid Extraction and Quality Control}

Corneal tissue was homogenized in Precellys ${ }^{\circledR} 24$ highthroughput tissue homogenizer (Bertin Corp., Rockville, MD, USA) using three 30-second cycles of homogenization at 5,500 rpm with $2.8 \mathrm{~mm}$ ceramic beads. Total RNA was extracted using NucleoSpin ${ }^{\circledR}$ RNA/Protein isolation kit (MACHEREY-NAGEL Inc., Bethlehem, PA, USA). Between 1 and $4 \mu \mathrm{g}$ of high-quality RNA was extracted from approximately half button as a starting material as measured by NanoDrop 2000c (ThermoScientific, Wilmington, DE, USA). Extracted RNA underwent quality assessment on Agilent 2100 Bioanalyzer (ThermoScientific) by visual examination of ribosomal bands and RNA integrity number ) calculation.

\section{Expression Profiling using $\mathbf{R T}^{2}$ Profiler PCR Array}

Ribonucleic acid was reverse transcribed to complementary deoxyribonucleic acid (cDNA) using RT $^{2}$ First Strand Kit (SABiosciences ${ }^{\circledR}$, Qiagen, Valencia, CA, USA). The Human Extracellular Matrix \& Adhesion Molecules RT ${ }^{2}$ Profiler PCR Array (PAHS-013Z, SABioscicences ${ }^{\circledR}$ ) was used to measure the expression levels of 84 individual genes important for cell-cell and cell-matrix interactions. Fluorescent signal was captured using ABI 7900 RealTime PCR System (Applied Biosystems ${ }^{\circledR}$, Life Technologies, Carlsbad, CA, USA).

\section{Analysis of differentially Expressed Genes}

The threshold cycle $(\mathrm{Ct})$ for each well was determined by real-time cycler software. Statistically significant differences in mean Ct values were determined using the $\mathrm{RT}^{2}$ Profiler PCR Array Data Analysis software V.3.5 (SABiosciences $\left.{ }^{\circledR}\right)$. The difference was considered significant when $p<0.05$ and $>1.5$ fold change. Genes with multiple undetermined $\mathrm{Ct}$ values in both $\mathrm{KC}$ and control samples were excluded from the final tables.

\section{Reference Housekeeping Genes for Normalization}

Reference genes beta-2-microglobulin (B2M), glyceraldehyde-3-phosphate dehydrogenase (GAPDH), hypoxanthine phosphoribosyltransferase 1 (HPRT), and ribosomal protein, large, $\mathrm{P0}$ (RPLP0) available on the PCR array were used for normalization of real-time PCR data. Beta actin (ACTB) was excluded from the list of reference genes due to its potential downregulation in the corneal stroma of patients with KC. . $^{17-19}$

\section{Genomic DNA Extraction}

Deoxyribonucleic acid was extracted from Epstein-Barr virus-transformed lymphoblastoid cell lines established from peripheral whole blood (sample IDs 2, 3, 6, 15, 18) ${ }^{20}$ or from corneal tissue (sample IDs 4, 5, 7, 8, 9, 10, 11, 12, $13,16,17)$ of the study participants using NucleoSpin Tissue kit (MACHEREY-NAGEL Inc.). Corneal tissue was homogenized by Precellys ${ }^{\circledR} 24$ high-throughput tissue homogenizer (Bertin) using three 45 -second cycles of homogenization at $5,500 \mathrm{rpm}$ with $2.8 \mathrm{~mm}$ ceramic beads.

\section{Single Nucleotide Polymorphism Genotyping}

COL5A1 single nucleotide polymorphisms (SNPs) rs7044529 and rs1536482 were genotyped using predesigned TaqMan ${ }^{\circledR}$ genotyping assays (Applied Biosystems ${ }^{\circledR}$ ) with allelic discrimination on ABI 7900 Real-Time PCR System (Applied Biosystems ${ }^{\circledR}$ ) using the manufacturer's protocols. 


\section{RESULTS}

\section{Patients}

We compared 13 corneal buttons obtained from KC patients with 4 corneal buttons from unaffected individuals used as controls (Table 1). The ages of KC patients varied from 18 to 59 (mean age $=34$ ) years and controls from 42 to 66 (mean age $=56$ ) years. All patients with KC had bilateral disease clinically; 12 out of $13 \mathrm{KC}$ patients were Caucasians, and 1 patient was Asian. Keratoconus patients were assigned a KC grade from mild to severe based on the average central keratometry readings obtained during videokeratography. In addition, we analyzed two corneal buttons from patients with unilateral corneal scarring (mean age $=53.5$ ) for which diagnosis of $\mathrm{KC}$ has been ruled out.

\section{Unsupervised Clustering Analysis}

Initial unsupervised clustering analysis of all 19 samples showed that gene expression profiles of KC corneas and corneas with scarring were clearly different from those of the control normal samples. Moreover, comparison of KC and scarring corneas revealed a number of differentially expressed genes (data not shown), suggesting that the development of KC and corneal scarring has different underlying mechanisms. However, due to the limited number of patients with corneal scarring, we could not perform accurate statistical testing of differences in gene expression, thus excluding scarring samples from further analysis. We also found a substantial difference in gene expression between Asian KC sample (see Materials

Table 1: Description of patients with $\mathrm{KC}$ and radial keratotomy-induced corneal scarring and controls

\begin{tabular}{llll}
\hline Sample ID & Affection & Age & KC Grade \\
\hline 2 & KC & 31 & Moderate \\
3 & KC & 39 & Moderate \\
4 & KC & 28 & Moderate \\
6 & KC & 32 & Moderate \\
7 & KC & 38 & Mild \\
9 & KC & 38 & Moderate-severe \\
10 & KC & 45 & Severe \\
12 & KC & 22 & Moderate \\
13 & KC & 59 & Mild \\
15 & KC & 18 & Moderate \\
17 & KC & 37 & Mild \\
18 & KC & 36 & Moderate \\
20 & KC & 19 & Severe \\
5 & Normal & 42 & NA \\
8 & Normal & 50 & NA \\
11 & Normal & 64 & NA \\
16 & Normal & 66 & NA \\
1 & Corneal scarring & 75 & NA \\
19 & Corneal scarring & 35 & NA \\
\hline
\end{tabular}

Sample IDs correspond to the identification of specimens in Figure 1 and throughout the text and Methods; Sample \#4, Table 1) and 12 Caucasian KC samples. To eliminate ethnicity as a potential confounding factor, sample \# 4 was excluded from further analysis. As shown in Figure 1, follow-up analysis of remaining

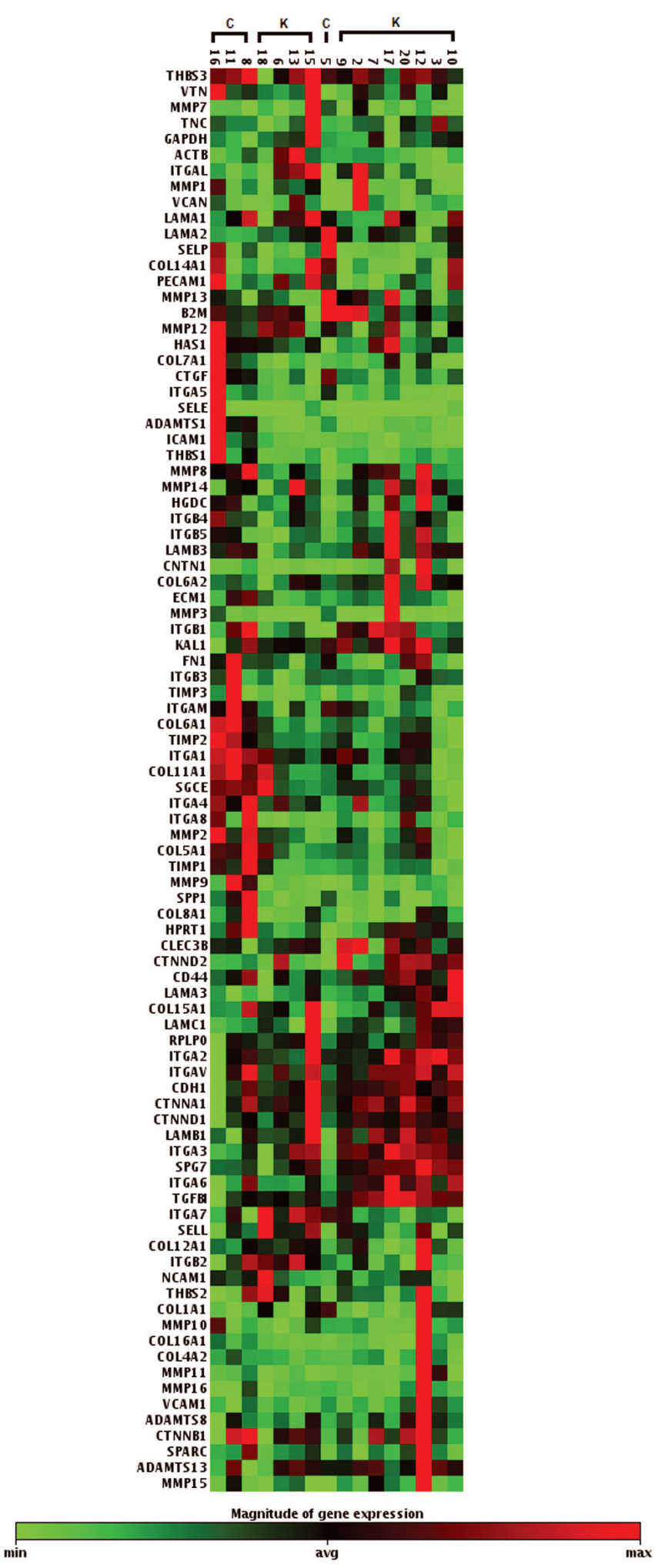

Fig. 1: Unsupervised clustering analysis of expression levels of genes assessed by the Human Extracellular Matrix \& Adhesion Molecules $\mathrm{RT}^{2}$ Profiler PCR Array in corneal RNA samples of KC patients $(K)$ and normal controls $(C)$. Samples are identified by their sample IDs as described in Table 1 and throughout the text 
16 human corneal profiles that included $12 \mathrm{KC}$ patients and 4 controls showed clear separation between KC RNA profiles and control RNA profiles and close clustering within each of these two groups (with the exception of control sample \#5).

\section{Identification of Genes differentially expressed in $\mathrm{KC}$ Corneas}

We compared mean Ct values of 63 genes (Table 2) present on the array which passed through the quality control (see Methods) between KC corneas and control corneas using $\mathrm{RT}^{2}$ Profiler PCR Array Data Analysis software and identified 21 differentially expressed genes; 16 genes were significantly downregulated in KC corneas (Table 3), while 5 were upregulated (Table 4).

Table 2: Expression of the Human Extracellular Matrix \& Adhesion Molecules pathway (PAHS-013Z) genes in KC corneas relative to normal (control) corneas. Bold font indicates significant results presented in Tables 2 and 3 in the main text. Genes with multiple undetermined $\mathrm{Ct}$ values in both $\mathrm{KC}$ and control samples were excluded

\begin{tabular}{|c|c|c|}
\hline Gene symbol & Fold change & $p$-value \\
\hline ADAMTS1 & -7.0555 & 0.000054 \\
\hline ADAMTS13 & 1.3622 & 0.128108 \\
\hline CD44 & 1.0321 & 0.733547 \\
\hline $\mathrm{CDH} 1$ & 1.8442 & 0.049092 \\
\hline CLEC3B & 2.4936 & 0.055671 \\
\hline COL11A1 & -2.2302 & 0.018245 \\
\hline COL12A1 & -1.0475 & 0.591674 \\
\hline COL15A1 & 1.2449 & 0.311979 \\
\hline COL16A1 & -1.3852 & 0.900884 \\
\hline COL4A2 & -1.1765 & 0.97383 \\
\hline COL5A1 & -1.853 & 0.020826 \\
\hline COL6A1 & -2.64 & 0.00123 \\
\hline COL6A2 & 1.2849 & 0.190442 \\
\hline COL7A1 & -3.8708 & 0.047511 \\
\hline CTGF & -3.7619 & 0.000065 \\
\hline CTNNA1 & 1.4091 & 0.058395 \\
\hline CTNNB1 & 1.0113 & 0.96793 \\
\hline CTNND1 & 1.5877 & 0.024713 \\
\hline ECM1 & -1.2376 & 0.435505 \\
\hline FN1 & -2.3972 & 0.037903 \\
\hline HAS1 & 1.0044 & 0.466643 \\
\hline ICAM1 & -4.9818 & 0.005024 \\
\hline ITGA1 & -1.7646 & 0.009838 \\
\hline ITGA2 & 1.503 & 0.133043 \\
\hline ITGA3 & 1.6382 & 0.005382 \\
\hline ITGA4 & -1.5996 & 0.142082 \\
\hline ITGA5 & -3.6704 & 0.001618 \\
\hline ITGA6 & 1.2341 & 0.133295 \\
\hline ITGAM & -3.729 & 0.000708 \\
\hline ITGAV & 1.2019 & 0.266128 \\
\hline ITGB1 & -1.0033 & 0.902853 \\
\hline ITGB2 & 1.0673 & 0.887152 \\
\hline ITGB4 & -1.0601 & 0.794764 \\
\hline ITGB5 & 1.0506 & 0.771635 \\
\hline
\end{tabular}

\begin{tabular}{lcl}
\hline & & \\
\hline Gene symbol & Fold change & $p$-value \\
\hline KAL1 & 1.2706 & 0.395259 \\
LAMA2 & 1.0707 & 0.935445 \\
LAMA3 & 1.3588 & 0.068293 \\
LAMB1 & 1.5471 & $\mathbf{0 . 0 1 2 2 2 6}$ \\
LAMB3 & -1.0945 & 0.885514 \\
LAMC1 & 1.3495 & 0.052668 \\
MMP12 & -1.6229 & 0.3032 \\
MMP14 & 1.3425 & 0.271504 \\
MMP2 & -1.7283 & 0.050682 \\
MMP3 & -9.3469 & 0.573376 \\
MMP9 & $-\mathbf{2 . 9 0 6 2}$ & $\mathbf{0 . 0 1 2 4 9 3}$ \\
NCAM1 & -1.3109 & 0.808807 \\
SELP & -3.2801 & 0.005178 \\
SGCE & -1.92 & 0.106972 \\
SPARC & -1.003 & 0.960997 \\
SPG7 & 1.3106 & 0.026446 \\
SPP1 & -11.534 & $\mathbf{0 . 0 0 0 2 0 4}$ \\
TGFBI & $\mathbf{1 . 6 5 5 7}$ & $\mathbf{0 . 0 0 4 4 3 5}$ \\
THBS1 & -1.5888 & $\mathbf{0 . 0 2 4 4 3 7}$ \\
THBS2 & 1.4394 & 0.494068 \\
THBS3 & -1.2297 & 0.209954 \\
TIMP1 & -1.5879 & $\mathbf{0 . 0 0 6 9 3 9}$ \\
TIMP2 & $\mathbf{2 . 0 3 1 4}$ & $\mathbf{0 . 0 0 6 8 1 1}$ \\
VCAM1 & 1.3394 & 0.618612 \\
ACTB & 1.1073 & 0.595505 \\
B2M & -1.0686 & 0.528366 \\
GAPDH & -1351 & 0.34958 \\
HPRT1 & & 0.087469 \\
RPLP0 & & \\
\hline & &
\end{tabular}

Table 3: Genes significantly downregulated in KC patients when compared with normal controls

\begin{tabular}{lll}
\hline Gene symbol & Fold change & $p$-value \\
\hline ADAMTS1 & -7.0555 & 0.000054 \\
COL11A1 & -2.2302 & 0.018245 \\
COL5A1 & -1.853 & 0.020826 \\
COL6A1 & -2.64 & 0.00123 \\
COL7A1 & -3.8708 & 0.047511 \\
CTGF & -3.7619 & 0.000065 \\
FN1 & -2.3972 & 0.037903 \\
ICAM1 & -4.9818 & 0.005024 \\
ITGA1 & -1.7646 & 0.009838 \\
ITGA5 & -3.6704 & 0.001618 \\
ITGAM & -3.729 & 0.000708 \\
MMP9 & -2.9062 & 0.012493 \\
SPP1 & -11.534 & 0.000204 \\
THBS1 & -1.5888 & 0.024437 \\
TIMP1 & -1.5879 & 0.006939 \\
TIMP2 & -2.0314 & 0.006811 \\
\hline
\end{tabular}

Table 4: Genes significantly upregulated in KC patients when compared with normal controls

\begin{tabular}{lll}
\hline Gene symbol & Fold change & $p$-value \\
\hline CDH1 & 1.8442 & 0.049092 \\
CTNND1 & 1.5877 & 0.024713 \\
ITGA3 & 1.6382 & 0.005382 \\
LAMB1 & 1.5471 & 0.012226 \\
TGFBI & 1.6557 & 0.004435 \\
\hline
\end{tabular}




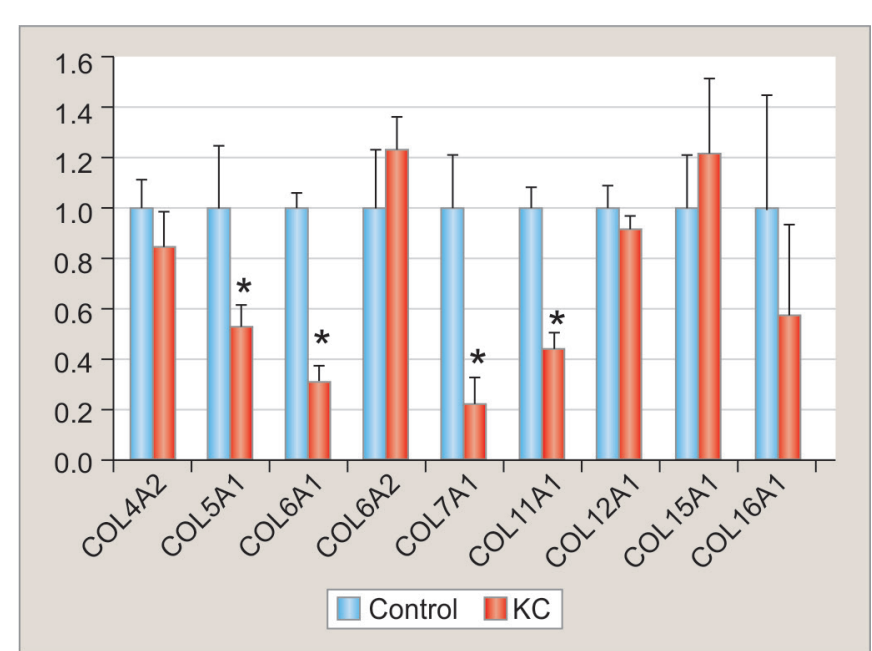

Graph 1: Expression levels of collagen genes in $\mathrm{KC}$ patients (red) and controls (blue). Fold difference is graphed on the $Y$ axis. *Statistically significant results

Among significantly downregulated genes, we identified a ubiquitous ECM glycoprotein fibronectin 1 (FN1), matrix metalloproteinase 9 (MMP9), two tissue inhibitors of metalloproteinases (TIMP1, TIMP2), three integrins (ITGA1, ITGA5, ITGAM), and four collagens (COL5A1, COL6A1, COL7A1, COL11A1). We have confirmed significant downregulation of thrombospondin 1 (THBS1) previously identified in the comparative transcriptome analysis of KC corneas. ${ }^{14}$ Interestingly, the expression levels of additional three collagen genes (Graph 1) were lower in KC patients when compared with controls. Notable novel genes we found downregulated in KC patients include disintegrin and metallopeptidase with thrombospondin type 1 motif gene (ADAMTS1) and secreted phosphoprotein 1 (SPP1).

Among genes upregulated in KC patients, we identified transforming growth factor beta-induced (TGFBI or BIGH3) gene associated with multiple types of corneal dystrophy (see Discussion) and laminin beta 1 gene (LAMB1) mutated in a zebrafish model of ocular coloboma. ${ }^{21}$ We also observed considerable upregulation of corneal epithelial keratinocyte-specific gene E-cadherin 1 (CDH1), integrin alpha 3 (ITGA3), and catenin (cadherinassociated protein) delta 1 (CTNND1).

\section{Comparison of COL5A1 Gene Expression in KC Patients and Controls with Different COL5A1 SNP Genotypes}

To test whether reduced expression of COL5A1 gene in $\mathrm{KC}$ patients is underlined by genetic variation, we have genotyped SNP rs1536482 located in the intergenic region between retinoid $X$ receptor alpha and COL5A1 genes and rs7044529 located in the intron of COL5A1 gene, both previously associated with $\mathrm{KC}$ in the genetic studies $^{2,3}$ (Table 5). Due to the limited number of samples,
Table 5: Genotyping results of KC patients and normal controls for SNPs and rs7044529 and rs1536482 located in and around COL5A1 gene

\begin{tabular}{llll}
\hline Sample ID & Affection & rs7044529 & rs1536482 \\
\hline 2 & $\mathrm{KC}$ & $\mathrm{C} / \mathrm{T}$ & $\mathrm{A} / \mathrm{G}$ \\
3 & $\mathrm{KC}$ & $\mathrm{C} / \mathrm{C}$ & $\mathrm{A} / \mathrm{G}$ \\
4 & $\mathrm{KC}$ & $\mathrm{C} / \mathrm{T}$ & $\mathrm{G} / \mathrm{G}$ \\
5 & Normal & $\mathrm{C} / \mathrm{C}$ & $\mathrm{A} / \mathrm{G}$ \\
6 & $\mathrm{KC}$ & $\mathrm{C} / \mathrm{T}$ & $\mathrm{A} / \mathrm{G}$ \\
7 & $\mathrm{KC}$ & $\mathrm{C} / \mathrm{C}$ & $\mathrm{A} / \mathrm{G}$ \\
8 & Normal & $\mathrm{C} / \mathrm{T}$ & $\mathrm{A} / \mathrm{G}$ \\
9 & $\mathrm{KC}$ & $\mathrm{C} / \mathrm{T}$ & $\mathrm{A} / \mathrm{G}$ \\
10 & $\mathrm{KC}$ & $\mathrm{C} / \mathrm{C}$ & $\mathrm{G} / \mathrm{G}$ \\
11 & $\mathrm{Normal}$ & $\mathrm{C} / \mathrm{C}$ & $\mathrm{A} / \mathrm{G}$ \\
12 & $\mathrm{KC}$ & $\mathrm{C} / \mathrm{C}$ & $\mathrm{A} / \mathrm{G}$ \\
13 & $\mathrm{KC}$ & $\mathrm{C} / \mathrm{T}$ & $\mathrm{A} / \mathrm{A}$ \\
15 & $\mathrm{KC}$ & $\mathrm{C} / \mathrm{T}$ & $\mathrm{A} / \mathrm{A}$ \\
16 & Normal & $\mathrm{C} / \mathrm{T}$ & $\mathrm{A} / \mathrm{G}$ \\
17 & $\mathrm{KC}$ & $\mathrm{C} / \mathrm{C}$ & $\mathrm{A} / \mathrm{G}$ \\
18 & $\mathrm{KC}$ & $\mathrm{C} / \mathrm{C}$ & $\mathrm{A} / \mathrm{G}$ \\
\hline
\end{tabular}

we identified no homozygotes (KC or normal) for KC risk allele T of rs7044529, only two KC patients' homozygous for risk allele A of rs1536482. In addition, we were unable to perform statistical testing of differences in the COL5A1 expression in samples stratified based on genotypes for SNP rs7044529 since two controls were CT heterozygotes and two were homozygous for major allele $\mathrm{C}$. Thus, we were only able to assess differences in COL5A1 expression in patients and controls heterozygous for risk allele at SNP rs1536482 and found that KC patients had lower COL5A1 expression compared with normal controls with the same genotypes; however, the difference did not reach statistical significance (fold change $=1.7, \mathrm{p}$-value $=0.06$ ) .

\section{DISCUSSION}

Using reliable real-time PCR-based method, we performed expression study of ECM molecules in patients with KC, controls, and small group of patients with corneal scarring. We identified threefold overabundance of downregulated genes, which is consistent with the destructive nature of the tissue degradation associated with $\mathrm{KC}$ and consistent with the transcriptome study of KC corneas. ${ }^{14}$

Some of the genes differentially expressed in KC tissue are novel candidates, whereas some have been implicated before. In addition, some of them are specific to $\mathrm{KC}$, while others have been described in other corneal pathologies. One of the notable newly identified downregulated genes is the SPP1 gene coding for SPP1 (also known as osteopontin) and an extracellular structural protein which participates in many physiological and pathological processes including wound and represents one of the most highly expressed proteins in corneal epithelial cells. ${ }^{22}$ Another notable newly identified 
downregulated gene is the one coding for ADAMTS1. Disintegrin and metalloproteinase with thrombospondin motif proteins are involved in the proteolytic modification of cell-surface proteins and ECM components essential for various natural and pathological processes, including wound healing and cell differentiation. ${ }^{23}$ Disintegrin and metalloproteinase with thrombospondin motif 1protein has been shown to be expressed by human corneal fibroblasts and to have a crucial role for normal growth and function of multiple tissues and organs, including supramolecular ECM structures of cornea and migration of corneal fibroblasts. ${ }^{24}$ Gene variants of another member of the same gene family ADAMTS6 were found to be associated with CCT (but not with KC). ${ }^{2}$ We also confirmed downregulation of THBS1 gene identified in high-throughput transcriptome analysis of KC corneas. ${ }^{14}$

Genes coding for seven out of nine corneal collagens available on the array and reliably present in the tested tissue samples were downregulated in KC corneas, including four with statistically significant $p$ values (Table 3 , Graph 1). This widespread downregulation could be used as a marker for KC. We observed decrease in the expression of COL5A1 gene in KC patients heterozygous for risk allele at SNP rs1536482 located in the COL5A1 genomic region when compared with normal controls with the same genotype (Table 5, Table 6). Further analysis of variation in COL5A1 gene is needed to identify variants responsible for the reduced expression of collagen $\mathrm{V}$ in KC patients.

We also found significant downregulation of MMP9, TIMP1, and TIMP2 in KC corneas, confirming their involvement in KC strongly suggested by others. ${ }^{25}$ However, conflicting results were identified in different studies of MMPs in KC tissue. ${ }^{26}$ Tissue inhibitors of metalloproteinases regulate proteolytic activity of MMPs by binding to the MMP active site, and thus, low level of TIMP expression may provide alternative mechanism of increasing activity of MMP9 in corneal stroma without increasing its expression levels.

Corneal structural integrity and repair processes largely depend on proper expression and function of integrins, important cell-surface molecules involved in cell-cell and cell-matrix interactions. ${ }^{27}$ Several integrins are expressed on the surface of keratocytes and mediate keratocyte-ECM interaction essential for corneal matrix maturation and corneal structural integrity. ${ }^{27}$ It has been reported that loss of integrin beta1 (which constitutes a

Table 6: Expression of COL5A1 gene in KC patients and controls heterozygous for risk alleles T and A of SNPs rs7044529 and rs1536482, respectively

\begin{tabular}{lll}
\hline SNP & Fold Change & $p$-value \\
\hline rs7044529 & -2.5 & 0.0003 \\
rs1536482 & -1.8 & 0.02 \\
\hline
\end{tabular}

part of important alpha5beta1 integrin) in keratocytes during stromal maturation results in corneal thinning. ${ }^{28}$ Here, we show that the decrease in the other component of the same complex, integrin alpha 1 (ITGA1), is significantly associated with $\mathrm{KC}$ in the analysis of corneal expression.

We observed upregulation of corneal epithelial keratinocyte-specific gene E-cadherin (CDH1). E-cadherin is involved in epithelial cell differentiation, ${ }^{29}$ and its increased expression had been identified in multipotent stem cells located in the corneal stroma with possible ability to transdifferentiate into corneal epithelial cells, ${ }^{30}$ indicating its importance in the mesenchymal-toepithelial transition-like processes. Another upregulated gene LAMB1 is elevated in corneas of lumican-deficient mouse corneas with stromal thinning. ${ }^{31}$

And lastly, we found significantly increased expression of TGFBI (BIGH3) in KC patients when compared with controls. Transforming growth factor beta-induced protein (TGFBIP, also frequently called BIGH3) is an extracellular protein that mediates cell adhesion to collagen, laminin, FN, and proteoglycans, like decorin and biglycan with expression changes triggered by TGFB signaling pathway activation. ${ }^{32}$ Transcript coding for TGFBI (BIGH3) was the second most abundant transcript identified in the cDNA library constructed from KC corneas by our group. ${ }^{33}$ Transforming growth factor beta-induced gene mutations have been frequently identified in patients with corneal dystrophies, a group of heterogeneous conditions that are characterized by the progressive loss of corneal transparency ${ }^{34}$ and lead to corneal abnormalities in transgenic mice. ${ }^{35}$ Recently, potential mutation in TGFBI was identified in Chinese KC patients. ${ }^{36}$ Transforming growth factor beta-induced protein has been identified in primary amyloid deposits of hereditary corneal dystrophies and in secondary amyloidosis of the cornea of diverse etiologies, ${ }^{37}$ as well as in corneal stromal amyloid deposits in KC patients. ${ }^{38}$ Increased levels of TGFBIP have been identified in corneas of patients with Fuchs' endothelial corneal dystrophy. ${ }^{39,40}$ Interestingly, we found elevated levels of TGFBI expression in patients with corneal scarring, similar to those in KC patients, when compared with normal controls (data not shown). Our results add to the mounting evidence that TGFBI is universally upregulated among patients with different corneal abnormalities.

\section{CONCLUSION}

Abnormal expression of a number of genes coding for important ECM proteins including a number of collagens is associated with the development of $\mathrm{KC}$ in corneal tissue. 


\section{CLINICAL SIGNIFICANCE}

Downregulation of corneal collagens and upregulation of TGFBI can be used as a potential screening and diagnostic tool for a variety of corneal abnormalities to assist corneal refractive surgeons with early diagnosis and prevention of laser-assisted in situ keratomileusisinduced complications.

\section{REFERENCES}

1. Rabinowitz YS. Keratoconus. Surv Ophthalmol 1998 JanFeb;42(4):297-319.

2. Lu Y, Vitart V, Burdon KP, Khor CC, Bykhovskaya $Y$, Mirshahi A, Hewitt AW, Koehn D, Hysi PG, Ramdas WD, et al. Genome-wide association analyses identify multiple loci associated with central corneal thickness and keratoconus. Nat Genet 2013 Feb;45(2):155-163.

3. Li X, Bykhovskaya Y, Canedo AL, Haritunians T, Siscovick D, Aldave AJ, Szczotka-Flynn L, Iyengar SK, Rotter JI, Taylor KD, et al. Genetic association of COL5A1 variants in keratoconus patients suggests a complex connection between corneal thinning and keratoconus. Invest Ophthalmol Vis Sci 2013 Apr 12;54(4):2696-2704.

4. Bykhovskaya Y, Li X, Epifantseva I, Haritunians T, Siscovick D, Aldave A, Szczotka-Flynn L, Iyengar SK, Taylor KD, Rotter JI, et al. Variation in the lysyl oxidase (LOX) gene is associated with keratoconus in family-based and case-control studies. Invest Ophthalmol Vis Sci 2012;53(7):4152-4157.

5. Dudakova L, Liskova P, Trojek T, Palos M, Kalasova S, Jirsova K. Changes in lysyl oxidase (LOX) distribution and its decreased activity in keratoconus corneas. Exp Eye Res 2012 Nov;104:74-81.

6. Davidson AE, Borasio E, Liskova P, Khan AO, Hassan H, Cheetham ME, Plagnol V, Alkuraya FS, Tuft SJ, Hardcastle AJ. Brittle cornea syndrome ZNF469 mutation carrier phenotype and segregation analysis of rare ZNF469 variants in familial keratoconus. Invest Ophthalmol Vis Sci 2015 Jan;56(1): 578-586.

7. Vincent AL, Jordan CA, Cadzow MJ, Merriman TR, McGhee $\mathrm{CN}$. Mutations in the zinc finger protein gene, ZNF469, contribute to the pathogenesis of keratoconus. Invest Ophthalmol Vis Sci 2014 Sep;55(9):5629-5635.

8. Stabuc-Silih M, Ravnik-Glavac M, Glavac D, Hawlina M, Strazisar M. Polymorphisms in COL4A3 and COL4A4 genes associated with keratoconus. Mol Vis 2009 Dec 20;15: 2848-2860.

9. Saravani R, Hasanian-Langroudi F, Validad MH, Yari D, Bahari G, Faramarzi M, Khateri M, Bahadoram S. Evaluation of possible relationship between COL4A4 gene polymorphisms and risk of keratoconus. Cornea 2015 Mar;34(3): 318-322.

10. Kenney MC, Nesburn AB, Burgeson RE, Butkowski RJ, Ljubimov AV. Abnormalities of the extracellular matrix in keratoconus corneas. Cornea 1997 May;16(3):345-351.

11. Maguen E, Rabinowitz YS, Regev L, Saghizadeh M, Sasaki T, Ljubimov AV. Alterations of extracellular matrix components and proteinases in human corneal buttons with INTACS for post-laser in situ keratomileusis keratectasia and keratoconus. Cornea 2008 Jun;27(5):565-573.

12. Joseph R, Srivastava OP, Pfister RR. Differential epithelial and stromal protein profiles in keratoconus and normal human corneas. Exp Eye Res 2011 Apr;92(4):282-298.
13. Chaerkady R, Shao H, Scott SG, Pandey A, Jun AS, Chakravarti S. The keratoconus corneal proteome: loss of epithelial integrity and stromal degeneration. J Proteomics 2013 Jul 11;87:122-131.

14. Mace M, Galiacy SD, Erraud A, Mejia JE, Etchevers H, Allouche M, Desjardins L, Calvas P, Malecaze F. Comparative transcriptome and network biology analyses demonstrate antiproliferative and hyperapoptotic phenotypes in human keratoconus corneas. Invest Ophthalmol Vis Sci 2011 Aug;52(9):6181-6191.

15. Nielsen K, Birkenkamp-Demtroder K, Ehlers N, Orntoft TF. Identification of differentially expressed genes in keratoconus epithelium analyzed on microarrays. Invest Ophthalmol Vis Sci 2003 Jun;44(6):2466-2476.

16. Shetty R, Sathyanarayanamoorthy A, Ramachandra RA, Arora V, Ghosh A, Srivatsa PR, Pahuja N, Nuijts RM, SinhaRoy A, Mohan RR, et al. Attenuation of lysyl oxidase and collagen gene expression in keratoconus patient corneal epithelium corresponds to disease severity. Mol Vis 2015 Jan;21:12-25.

17. Lee JE, Oum BS, Choi HY, Lee SU, Lee JS. Evaluation of differentially expressed genes identified in keratoconus. Mol Vis 2009 Nov 28;15:2480-2487.

18. Joseph R, Srivastava OP, Pfister RR. Downregulation of betaactin gene and human antigen $\mathrm{R}$ in human keratoconus. Invest Ophthalmol Vis Sci 2012 Jun;53(7):4032-4041.

19. Srivastava OP, Chandrasekaran D, Pfister RR. Molecular changes in selected epithelial proteins in human keratoconus corneas compared to normal corneas. Mol Vis 2006 Dec 20;12:1615-1625.

20. Pressman S, Rotter JI. Epstein-Barr virus transformation of cryopreserved lymphocytes: prolonged experience with technique. Am J Hum Genet 1991 Aug;49(2):467.

21. Moosajee M, Gregory-Evans K, Ellis CD, Seabra MC, GregoryEvans CY. Translational bypass of nonsense mutations in zebrafish rep1, pax2.1 and lamb1 highlights a viable therapeutic option for untreatable genetic eye disease. Hum Mol Genet 2008 Dec 15;17(24):3987-4000.

22. Vereb Z, Albert R, Poliska S, Olstad OK, Akhtar S, Moe MC, Petrovski G. Comparison of upstream regulators in human ex vivo cultured cornea limbal epithelial stem cells and differentiated corneal epithelial cells. BMC Genomics 2013 Dec 17;14:900

23. Tang BL. ADAMTS: a novel family of extracellular matrix proteases. Int J Biochem Cell Biol 2001 Jan;33(1):33-44.

24. Ducros E, Berthaut A, Mirshahi P, Lemarchand S, Soria J, Legeais JM, Mirshahi M. Expression of extracellular matrix proteins fibulin- 1 and fibulin- 2 by human corneal fibroblasts. Curr Eye Res 2007 Jun;32(6):481-490.

25. Balasubramanian SA, Pye DC, Willcox MD. Are proteinases the reason for keratoconus? Curr Eye Res 2010 Mar;35(3): 185-191.

26. Collier SA. Is the corneal degradation in keratoconus caused by matrix-metalloproteinases? Clin Experiment Ophthalmol 2001 Dec;29(6):340-344.

27. Stepp MA. Corneal integrins and their functions. Exp Eye Res 2006 Jul;83(1):3-15.

28. Parapuram SK, Huh K, Liu S, Leask A. Integrin beta1 is necessary for the maintenance of corneal structural integrity. Invest Ophthalmol Vis Sci 2011;52(11):7799-7806.

29. Pontoriero GF, Smith AN, Miller LA, Radice GL, West-Mays JA, Lang RA. Co-operative roles for E-cadherin and N-cadherin 
during lens vesicle separation and lens epithelial cell survival. Dev Biol 2009 Feb 15;326(2):403-417.

30. Hashmani K, Branch MJ, Sidney LE, Dhillon PS, Verma M, McIntosh OD, Hopkinson A, Dua HS. Characterization of corneal stromal stem cells with the potential for epithelial transdifferentiation. Stem Cell Res Ther 2013 Jun 24;4(3):75.

31. Shao H, Chaerkady R, Chen S, Pinto SM, Sharma R, Delanghe B, Birk DE, Pandey A, Chakravarti S. Proteome profiling of wild type and lumican-deficient mouse corneas. J Proteomics 2011 Sep 6;74(10):1895-1905.

32. Engler C, Chakravarti S, Doyle J, Eberhart CG, Meng H, Stark WJ, Kelliher C, Jun AS. Transforming growth factorbeta signaling pathway activation in Keratoconus. Am J Ophthalmol 2011 May;151(5):752-759.e2.

33. Rabinowitz YS, Dong L, Wistow G. Gene expression profile studies of human keratoconus cornea for NEIBank: a novel cornea-expressed gene and the absence of transcripts for aquaporin 5. Invest Ophthalmol Vis Sci 2005 Apr;46(4):1239-1246.

34. Kannabiran C. Genetics of corneal endothelial dystrophies. J Genet 2009 Dec;88(4):487-494.

35. Bustamante M, Tasinato A, Maurer F, Elkochairi I, Lepore MG, Arsenijevic Y, Pedrazzini T, Munier FL, Schorderet DF.
Overexpression of a mutant form of TGFBI/BIGH3 induces retinal degeneration in transgenic mice. Mol Vis 2008 Jun 13;14:1129-1137.

36. Guan T, Liu C, Ma Z, Ding S. The point mutation and polymorphism in keratoconus candidate gene TGFBI in Chinese population. Gene 2012 Jul 15;503(1):137-139.

37. Suesskind D, Auw-Haedrich C, Schorderet DF, Munier FL, Loeffler KU. Keratoepithelin in secondary corneal amyloidosis. Graefes Arch Clin Exp Ophthalmol 2006 Jun;244(6): 725-731.

38. TaiTY,Damani MR, Vo R, Rayner SA, Glasgow BJ,Hofbauer JD, Casey R, Aldave AJ. Keratoconus associated with corneal stromal amyloid deposition containing TGFBIp. Cornea 2009 Jun;28(5):589-593.

39. Jurkunas UV, Bitar M, Rawe I. Colocalization of increased transforming growth factor-beta-induced protein (TGFBIp) and Clusterin in Fuchs endothelial corneal dystrophy. Invest Ophthalmol Vis Sci 2009 Mar;50(3):1129-1136.

40. Weller JM, Zenkel M, Schlotzer-Schrehardt U, Bachmann BO, Tourtas T, Kruse FE. Extracellular matrix alterations in late-onset Fuchs' corneal dystrophy. Invest Ophthalmol Vis Sci 2014 Jun;55(6):3700-3708. 